\title{
The Impact of Algorithm on Local Journalism: A Comparative Study on Report of Wuxi's Bridge Collapse in 2019
}

\author{
Hai Tang, Lihong Qi, Xiao Zhang \\ School of Foreign Languages, Wuxi Taihu University, Wuxi, China \\ Email: carlatube@qq.com
}

How to cite this paper: Tang, H., Qi, L. H., \& Zhang, X. (2020). The Impact of Algorithm on Local Journalism: A Comparative Study on Report of Wuxi's Bridge Collapse in 2019. Advances in Journalism and Communication, 8, 69-79.

https://doi.org/10.4236/ajc.2020.83006

Received: July 7, 2020

Accepted: August 10, 2020

Published: August 13, 2020

Copyright $\odot 2020$ by author(s) and Scientific Research Publishing Inc. This work is licensed under the Creative Commons Attribution International License (CC BY 4.0).

http://creativecommons.org/licenses/by/4.0/

\begin{abstract}
The Bridge Collapse event in Wuxi in October last year attracted the attention of several domestic media outlets. The news was simultaneously known to readers when the accident took place. Compared with the rapid coverage of the big media, the local media in Wuxi chose to report on the news after two days. The two different attitudes of the media on report of accident news arguably reflected the way of algorithmic news working in context of network society, where local news is accessible from more and more different sources, and where transparency and accountability shall be kept as key tenet of journalism ethics. This paper criticized the local media in Wuxi by elucidated its limitation in aware of accident news as algorithmic as reportable from a series of layers such as immediacy, newsworthy, interactive mode, etc. It also suggests that the challenge of using algorithms is to develop journalistic professionalism, including critique, the use of transparency and concern for public opinions.
\end{abstract}

\section{Keywords}

Transparency, Accountability, Local Journalism, Bridge Collapse Event in Wuxi, Algorithmic News

\section{Introduction}

The network society is opening up new frontiers and transforming journalism in ways that nobody can predict. Newsroom uses intelligent methods and technologies to increase the scope of searching for news and improve the quality of news stories, making messages more accurate by editing them based on data (Cui \& Wu, 2019) such as Newspad, a US start-up, provides $21^{\text {st }}$-century radar system for news organizations in the States to help media search more reporting 
resources, allowing them to quickly make decisions on news report. In addition, in the context of the Internet, due to a continuous expansion of the news ecosystem, media organizations are likely to disseminate news by tracking the interests of readers and audiences. Take Toutiao, it uses algorithms to publish news to attract readers. In other words, what Toutiao tries to achieve is the algorithmic news that can be used to recommend personalized content to users ( $\mathrm{Lu}$, 2019: p. 12). Moreover, in the information age, media have to find a way to keep pace with the growing scale of the news if their aim truly is to showcase professionalism. The news media in Guiyang, Guangxi, for example, put green and ecological development as main themes of news reporting over the years, and have greatly enhanced the regional image of Guangxi Province (Yang, 2016: p. 72).

The above imply that, the spread of news stories has been accelerated in network society, but without a mechanism for enhancing content mining, it is hard to achieve an appropriate level to disseminate news reporting. In recent years, the popularity and development of social media have potentially "threatened" local media, take Wuxi, the loss of local news audience, the drop of local news circulation, and the shrinking of advertising revenue (Wu, 2015: p. 68), all of which are existing problems of how local media actually rethink about media effect under the net. In other words, media may not meet the needs of attention if they only bring fragmented information, more attention shall be devoted to whether the news recommendation is accurately matching readers' interest, emphasizing the importance of local news content, or aware of the importance of reporting any incident from daily life (Zheng, 2018: p. 57). Then, how do journalists and editors of local media scientifically apply algorithm to the practice of news dissemination, and how can local media better serve their audiences in the age of big data, further, how can local media capture the value of shaping and promotion of local journalism? This paper will use the report on 2019 Bridge Collapse in Wuxi as a case to answer the questions.

The structure of the paper is arranged in six parts. Apart from the above content set as an introductory one, the second part is the analyses of the declining priority of local newspaper. It argues that, the means of algorithm may rely on elements of news subject to improve the predictive nature of news coverage. In this way, media potentially "decode" what their audiences prefer to read. The third part introduces how big media paid attention to Wuxi's accidental event in 2019, and how local media in Wuxi treated the news. It again argues, that difference between the two media attitudes, especially the processing of immediacy or the principle of notification in doing journalism, is an alternative reflection of news filtering as well as an alternative form of journalistic algorithm. The fourth part looks back at the 2019 Wuxi event by analysing public discussions of the accident in Xiakedao. It finds out that at the core of the problem is a lack of accountability of the local media. The next section offers further discussions of media reportage on the 2019 Wuxi event, and suggests that the use of algorithm shall focus not only on Uses and Gratifications, but also on Agenda-Setting. The last part cla- 
rifies effective strategies for algorithmic approaches in doing local journalism, including the emphases on both organizational and readership-based incentives.

\section{Algorithmic Power, News and the Declining Priority of the Local Newspaper}

As a new type of news reporting, the algorithm helps traditional journalism in reporting and editing news production. One of the features of algorithmic news is that, it uses smart technology to recommend personalized content to users by matching computing algorithms or data (Pasquale, 2011). Scholars believe that algorithmic news has a structural effect on news producing and news disseminating, as Fang Shishi (2016: p. 43) argued, that the term "professionalism" may be constantly challenged, due to the reading of the news may be determined by algorithm rules such as hot-searches or the interests of the audiences. In talking about algorithmic hot-searches set by online media, Wang Xiaoxin (2013: p. 41) claimed that hot-searches is an expanding approach of Uses and Gratifications, leading the media to pay more attention to their audiences, thus, to measure the effectiveness or the quality of news dissemination.

In addition, it is expected that algorithmic news can help readers get informed, and this is in part the way of such news functioned as public surveillance, offering users the chance to access to information on societal reality (Gillespie, 2014). Moreover, as transparency has gradually become the responsibility among journalists who are seeking to build public trust, it is possibly seen algorithm as new pillar of journalistic ethics (Seaver, 2013). To some extent, transparency can be a standard lever brought by algorithmic power when disclosing information becomes the motivation. It can be seen that the transparency in algorithmic journalism conforms to the norms of journalistic professionalism. In other words, media is required to evince authenticity, claim objectivity and take responsibility (Ye, 2020: p. 109), offering the public truthful and accurate news stories.

The emergence of algorithmic news has also made journalism, especially the local media higher demands on how they report the news. However, journalism scholars have been warning of a bleak present and worse future for local and regional media, that newspaper circulation is declining, and advertising revenues are shrinking, as mentioned in previous section. This means that local newspaper enjoying a dominant position within their circulation areas, facing only limited competition from regional and national media now comes to be a "history", due to an intense competition comes along with the rapid growth of digital media. As a result, local journalism has been tied with a wider change, where readers, news dissemination, and the interactive circulation in networks have forced it to increasingly face the challenge, not only of covering local affairs, but also of identifying in ways that resonate with their readers in terms of what is local, what makes it local, and why the local is relevant.

The application of smart-based technology in doing journalism is now embodied in news reporting, news editing, news dissemination and news con- 
sumption. New modes such as sensor news, algorithm recommendation, immersion-in-news emerge in news rooms. (Wang, Zhang, \& Wu, 2018: p. 38)

On the other side of the coin, the potential trend that readers relying on wider and diverse digital and social media to be informed, involved and interacted is increasingly obvious. Today, news topics have online components and manifestations on social networking sites such as WeChat and WeChat Public Accounts, disseminating information produced by non-journalists and drawing netizens' attention to issues of common concern. As Jiang Dan argued:

A "clicking" way regularly used by WeChat users in their Moments is to show a fast-food reading style. While in a short-term, it can provide users a choice or reference for their selection of picking up information. (Jiang, 2019: p. 78)

Such a reality underlines that even in cities where there is only one or a few local newspapers, local media will no longer have a monopoly on providing local information as local readers have other sources to get news. In this sense, the challenge for local newspapers is accompanied by considerable significance that the call for a positive image of the news-communicative environment would be well supported. For example, Zhuang Yangxiao (2018), a journalist from Fujian province, researched on Hyper Local News Websites in the US, and found that the core of the local journalism is the use of localization, connecting local news with public participation to achieve sustainable development.

With social networks playing a big role in the expansion of the news ecosystem, local newspapers are asked to keep constant track of what is happening among readers in real time. In addition to the scale, the scope and the speed of disseminating the news, it is noticeable that the digital media have changed the nature of the relationship with their audiences, providing an immediate, informative and interactive platform for dialogue, debate and discussion. As Nicholas Diakopoulos noted:

Embedded in every prioritization algorithm are criteria that are computed and used to define a ranking through a sorting procedure. These criteria embed a set of choices and value-propositions, which may be political or otherwise biased, that determine what gets pushed to the top. (Diakopoulos, 2015: p. 401)

Algorithmic journalism has certain limitations. The function of the gatekeeping, for instance, may be restricted due to the control of computing technology such as the use of searching engines, leading to the spread of fake news. In August 2016, Facebook set Fox News Exposes Traitor Megyn Kelly, Kicks Her out for Backing Hillary as a hot topic, causing a lot of negative effects because of its fakeness. (Carlson \& Zhang, 2018: p. 94)

The example of the Facebook suggests that algorithms may become a new gatekeeper in doing journalism. In other words, algorithm as the one of the smart technologies used in news media, it produces algorithmic news by data extraction, linguistic analyses and so on so forth, but the interpretation of algorithmic 
results is embedded in the process of computing algorithm, leading to a depreciation of the value in journalism (Carlson \& Zhang, 2018: p. 93). The emergence of "traffic stars" probably can be seen as a typical, that the importance of the news gives way to entertainment information, contributing to an algorithmic push of the media.

Even though algorithm may be considered as unreasonable at some point, algorithmic news has entered into journalistic domain and played a role in practice. It can be seen that the arrival of algorithmic news has led to the development of media communication from its linear mode toward "algorithmic recommendation". It in turn makes a request to local journalism for being urged for change, as it has to face diverse professional practices within the field, including a collaborative filtering system run to filter information that is delivered as "meaningful" to readers. The report on the Bridge Collapse in Wuxi in 2019 was a case in point.

\section{Media Reportage on Wuxi Bridge Collapse in 2019}

On $10^{\text {th }}$ of October, a bridge collapse happened at $6 \mathrm{PM}$ in Wuxi. China's state news agency People's Daily immediately informed the public (see Figure 1). "Three people died and two were injured when a highway bridge collapsed on Thursday in China's eastern part of Jiangsu province"'.

Caixin Global, one of China's famous financial magazines reported the event in detail (see Figure 2): "[M] any large vehicles were presented on the bridge at the time, one of which was a truck carrying six large coils of steel"2.

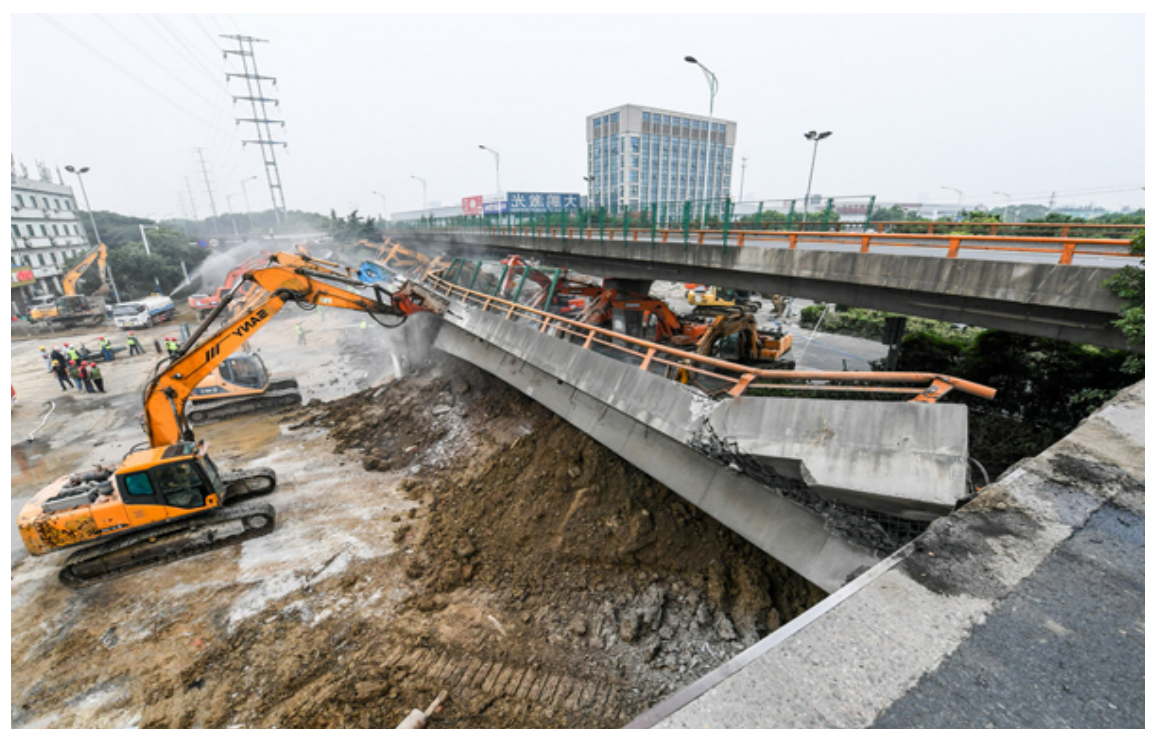

Figure 1. The scene of the accident. Source: Xinhua/Photo by Li Bo.

${ }^{1}$ See Three Dead in East China's Highway Overpass Collapse (11, October, 2019, Xinhua). Available at http://en.people.cn/n3/2019/1011/c90000-9621747.html, accessed on 2 July 2020.

${ }^{2}$ See In Depth: Overloaded and Overturned: Inside the Deadly Wuxi Bridge Collapse (10, October, 2019, Bao Zhiming, Tan Jianhang, Wang Mengyao, Xiang Siqi, and Huang Yuxin). Available at: https://www.caixinglobal.com/2019-11-01/in-depth-overloaded-and-overturned-inside-the-deadlywuxi-bridge-collapse-101478011.html, accessed on 2 July 2020. 


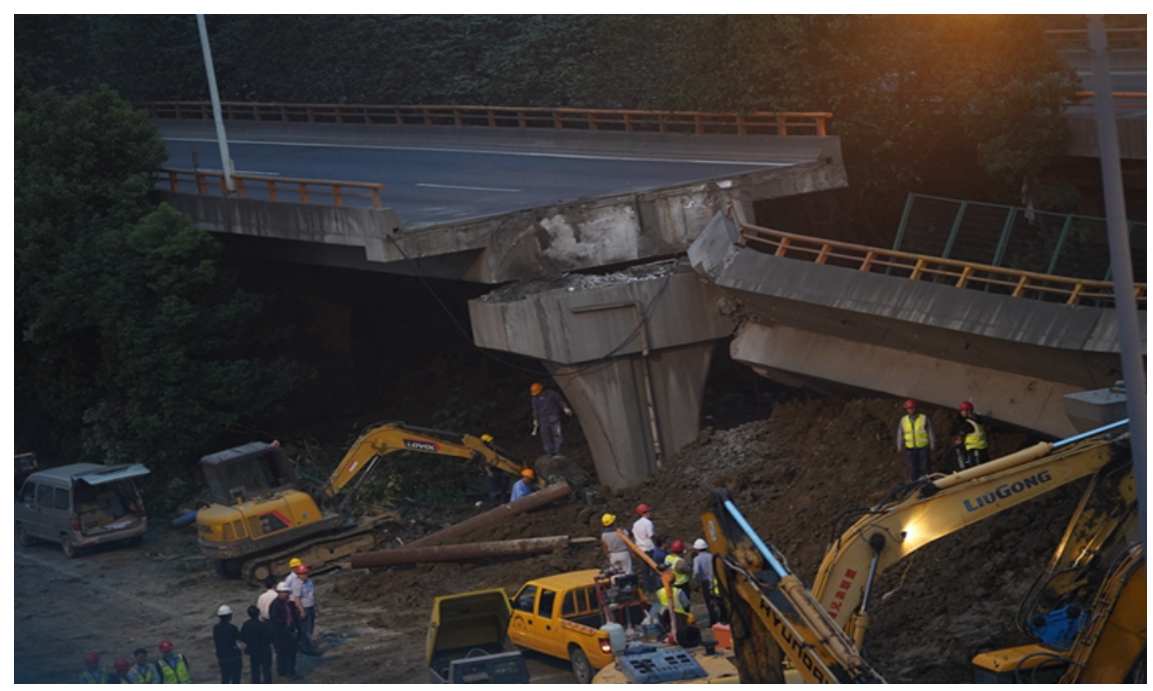

Figure 2. The scene of the accident. Source: Caixinglobal/Photo by Ding Gang.

And on $11^{\text {th }}$ of October, China's popular commercial portal site Sohu.com released the same news under a title "Overloading Suspected as Cause of Wuxi Viaduct Collapse", implying the way the event happened ${ }^{3}$.

However, the accident was quoted by the local news site Wuxinews.com.cn after two days and it said that "The collapse of an overpass in Wuxi... killed three and injured two", while it used "may have been caused by overloaded vehicles" as its overall tone ${ }^{4}$.

From the above titles, contents and tones of the reports on Wuxi's Bridge Collapse it can be seen how national and regional online media practiced algorithm in making local journalism. People's Daily stood out as the one that paid significant attention to "speedy", concerning of an attitude of how to enhance the timeliness of the news.

Unlike People's Daily, both the commercial-oriented Caixin Global and Sohu.com focused on a "social issue" with the audiences, relating to Wuxi's transportation demand management, which can easily touch the sensitive nerves of local residents.

In this sense, transparency and identifying newsworthy are two standards for articulating algorithmic power. In other words, in reporting on the Wuxi Bridge Collapse event, big media made their reportage decisions either on fact-finding for algorithms, or the employment of critical journalism for algorithmic practice.

While a hesitative attitude of Wuxi media reflected the limitation of local media in doing local journalism. Take the 2019 October event in Wuxi, a "filtering-out" or delaying decision was exerted probably due to certain censorship from local government, thus the local media in Wuxi producing the content was in contrary to media ethics as well as the interest of audiences, their right to ${ }^{3}$ See Overloading Suspected as Cause of Wuxi Viaduct Collapse (in Chinese, 11, October, 2019). Available at https://m.sohu.com/a/346292445_740946/, accessed on 2 July 2020.

${ }^{4}$ See Overloading Suspected as Cause of Bridge Collapse (12 October 2019, China Daily/Caoyin and Zhang Zhuoxiang). Available at: http://www.wuxinews.com.cn/2019-10/12/c 415302.htm, accessed on 2 July 2020. 
know the truth (Sha, 2019). The latter issue recalls critical thinking of media effect under the background of professionality, that is, how to embed the news principle of accountability in the process of algorithmic construction? Probably Xiakedao's reporting mode can offer an answer.

\section{Accountability: A Journalistic Use of Algorithm in Doing Local Journalism}

The delayed coverage of local accident on Wuxi media mentioned above, if talking about journalistic professionalism in the context of algorithm, can also be seen as the lack of algorithmic accountability. Take 2019 Wuxi Bridge Collapse, "social issue" as a prominent theme reported in both authorial and local media, and the word "overloading" as the crux of the tragic accident got confirmative and sustainable coverage, though, the use of "may have" on http://www.wuxinews.com.cn/ had caused a lot of public discontent. A commentary article $A$ Tragedy Caused by Overloading, written by Xiakedao, an official WeChat Public Account of People's Daily argued that:

There are quite a few cross-cutting problems in the practice of governance: as for Wuxi's accident, both traffic police and transportation department are capable to control, but they may not prefer to control, or they may not manage to control. (24 October 2019)

The commentary article published by Xiakedao revealed the importance of the role and responsibility of transportation-governance. It implicitly suggested the local media in Wuxi to take an active role in setting public agenda, exploring deep-seated causes of the accident and criticizing failures of governmental regulations led to this damage. Xiakedao's report quickly aroused netizens to post their sharp and critical comments:

The article lists a lot of regulatory difficulties, but if we always think about responsibilities, do we still have so many accidents? (cited in Yeyeyeye Qi, October 24, 2019)

Overloading is a serious issue in this event, but the inner defects inside that single pier bridge should be an attentive problem as well. (cited in Miwu Senlin, October 24, 2019)

Accidents like bridge collapse are lack of systematic thinking, and are the inevitable outcome of rough and disordered management. (cited in Tzar, October 24, 2019)

From netizens' comments it can be seen that, critical words and phrases such as "responsibilities", "inner defects" and "lack of systematic thinking" were perceived as significant. They emphasized the function of the local media in doing local journalism. That is, to set the news media as an interactive platform, collecting feedbacks of the local news to attract public participation. Additionally, ${ }^{5}$ See $A$ Tragedy Caused by Overloading (in Chinese, 24, October, 2019, Xiakedao/Lv Dewen). Available at: http://dxshare.dianzhenkeji.com/sehui/article/1/1187374356741885952, accessed on 3 July 2019. 
netizens' critical comments were diverse but their demand was for digging or solving societal problems. To some extent, such emphasis and demand are in relation to algorithm accountability (Diakopoulos \& Koliska, 2017).

\section{Findings with Discussion}

The topic of this article is about the use of algorithm in doing local journalism, and it takes the 2019 Bridge Collapse in Wuxi as an example. The paper presented above including how People's Daily, Caixin Global, Sohu.com and other media reported on the news, how local media in Wuxi treated the event, and how Xiakedao and its readers caught the news bulletin. Thus, it argues that the story of the Bridge Collapse in Wuxi can be seen as the assessment of algorithmic transparency and algorithmic accountability for news media, rationally applying Agenda-Setting to their online version, In other words, big media considered Wuxi's accident as breaking news, hot news and civic news as their ranking content, practicing dialogicality with their audiences, the aim was to shift their report from an average focused to an opinion-oriented news (Chen, 2012: p. 3).

Firstly, news stories are typical "experimental goods" in digital age, whether they are suitable for consumers' taste can only be judged after consumption (Sha, 2019). The news market produces diverse and massive contents every day, and they are classified and filtered in order to produce societal value. In this context, effective matching via modern algorithms becomes necessary, as it can transform news into a set of contents that meet the needs and interests of social groups. Therefore, news content is a key factor in determining the degree of audiences' acceptance or public trust (Niu, 2019: p. 23).

Secondly, an obvious benefit in an Internet-plus era is that, audiences are easier to find a variety of media contents, but the process of searching for news includes not only the media providing general news, but also suggestions, comments and a range of other technologies to help audiences get what they want to view. In comment on Wuxi's Bridge Collapse in 2019, netizens actively participated because they consider Xiakedao as a major drive for public opinions. And this in part indicates the efficacy of algorithm, as Nicholas Diakopoulos and Michael Koliska noted:

There are two distinct avenues for transparency, one concerning the editorial human influences and decisions in modeling and methodology, and the other concerning how those editorial choices are implemented in code. There was a belief by some participants that such editorial decisions in the modeling process would lead to deeper insights about the news organization (Diakopoulos \& Koliska, 2017: p. 11).

Thirdly, civic news is of great value in shaping the image of government, and pushing regional and societal development (Yang, 2020: p. 46). As news organizations come to employ algorithms in shaping of the news they report, journalistic standards for accountability as algorithm will need to be developed. For instance, in report on Wuxi's Bridge accident in 2019, the local media might con- 
sider the risks of disclosure, or the negativity of its immediate disclosure, including the negative experience of readers for communicating with that disclosure, accordingly, it left audiences and other media a negative impression.

While the online discussion of the 2019 Bridge Accident in Xiakedao provided a legitimate reason for digital media to stick to their follow-up reports on sensitive issues. In other words, big media have changed the ways for Chinese journalists to do their job, that is, they eager to pick up issues and make them as first-become-known reports on their digital platforms, as People's Daily and Xiakedao had done. The two modes, concerning transparency in news report and awareness of the necessity of public opinion can be seen as journalistic mode of algorithm and should be particularly applied to local media, reshaping the quality of local journalism.

\section{Conclusion}

Local journalism today is changing in part because of a boosting and competitive digital environment undoubtedly represents considerable potential for inspiring its new forms. Report on the October Wuxi Accident in 2019 possibly showed that local journalism can be produced as algorithmic information, with networked sharing contents displayed on China's kinds of digital media. While the critical comments from netizens claimed that, they pushed local newspapers to continue thinking the way, not of promoting print circulation, but of attracting print readership by making professional local journalism.

Beyond local media and local journalism, algorithmic news potentially helps readers stay informed about local public affairs, mobilising them to get engaged, as can be seen in Xiakedao. While it has to acknowledge that, when readers and audiences have the chance to access to more and more digital platforms, they may have less interest to access regularly to local newspapers. Then the gap will grow between a shrinking minority who concern about local news and a growing majority who do not frequently follow the local media. The risk seems to warn that local news media may become weaker constantly in holding power in terms of keeping their readers informed, or fostering community integration than they did in the past. While the experience from People's Daily, Caixin Global, Xiakedao and other media suggests that an algorithmic news system they considered is more oriented toward information disclosure and media accountability. Such orientation may also provide a motivating path for local media to do local journalism.

Even though local journalism performed by local media was far from ideal, it has been essentially or necessarily proved as an important source of public information, and a part of public concern or engagement. Take the Wuxi accident in 2019, it acted as a journalistic source and presented by types of reportage in telling their readers where the story came from, how they saw the accident and what issue they focused on. Each of the details can be read as a particular or alternative aspect in connection with the impact of algorithm on local journalism, and shown as a positive side of China's news-room. 


\section{Conflicts of Interest}

The authors declare no conflicts of interest regarding the publication of this paper.

\section{References}

Carlson, M., \& Zhang, J. Z. (2018). Automating Judgment? Algorithmic Judgment, News Knowledge, and Journalistic Professionalism. Shanghai Journalism Review, 3, 83-96.

Chen, Y. (2012). On the Innovation of Agenda-Setting: From Reporting to Opinion-Led Reporting in Doing Journalism. Journalism Lover, 10, 3-5. (In Chinese)

Cui, D., \& Wu, F. (2019). The Knowledge Effect of Algorithms on News Report: Take Toutiao as an Example. Shanghai Journalism Review, 2, 30-36. (In Chinese)

Diakopoulos, N. (2015). Algorithmic Accountability. Digital Journalism, 3, 398-415. https://doi.org/10.1080/21670811.2014.976411

Diakopoulos, N., \& Koliska, M. (2017). Algorithmic Transparency in the News Media. Digital Journalism, 5, 809-828. https://doi.org/10.1080/21670811.2016.1208053

Fang, S. S. (2016). The News Values Behind the Algorithms: A Study of Facebook. Shanghai Journalism Review, 9, 39-50. (In Chinese)

Gillespie, T. (2014). The Relevance of Algorithms. In T. Gillespie, P. Boczkowski, \& K. Foot (Eds.), Media Technologies: Essays on Communication, Materiality, and Society (pp. 185-193). Cambridge, MA: MIT Press. https://doi.org/10.7551/mitpress/9780262525374.001.0001

Jiang, D. (2019). Exploring the Motivation and Significance of Sharing the Reading in WeChat Moments Media Forum, 11, 76-78. (In Chinese)

Lu, X. L. (2019). Algorithmic News: Problems and Challenges under the Transformation of Technology. Social Sciences Digest, 5, 11-13. (In Chinese)

Niu, J. (2019). Transparency in News: A New Code of Media Ethics under Technological Transformation. News and Writing, 4, 22-28. (In Chinese)

Pasquale, F. (2011). Restoring Transparency to Automated Authority. Journal of Telecommunications \& High Technology Law, 9, 235-256.

Seaver, N. (2013). Knowing Algorithms. Media in Transition, 8, 1-12.

Sha, J. (2019). Reform and Innovation of Local News Broadcasting in the Age of Media Integration. Media Forum, 5, 91. (In Chinese)

Wang, J., Zhang, Y., \& Wu, S. (2018). On the Change and Reflection of News Dissemination in the Background of Artificial Intelligence. Press Outpost, 9, 38-39. (In Chinese)

Wang, X. X. (2013). The Online Reading Habit and Reading Tendency of the Audiences in Contemporary China-Take Hot Search Words on Baidu. Today's Massmedia, 9, 41-42. (In Chinese)

Wu, W. H. (2015). The Exploration and Development of Media Integration in Wuxi Science and Technology for China's Mass Media, 5, 68-69. (In Chinese)

Yang, C. (2020). The Influence of Algorithmic Recommendation on Audiences and Its Relative Strategies. New Media Research, 10, 45-47+60. (In Chinese)

Yang, Z. Y. (2016). Research on the Relations between Environmental News and the Shaping of Regional Image. News Tribune, 5, 72-76. (In Chinese)

Ye, X. R. (2020). The Reconstruction and Practical Route of Journalistic Professionalism in Algorithmic Journalism. Journal of Huaqiao University (Philosophy \& Social Science), 2, 108-116. (In Chinese) 
Zheng, Y. J. (2018). From Focus on Content to Focus on the Platform: The Case of "Big and Small News". Shangdong Daily Youth Journalist, 14, 57-58. (In Chinese)

Zhuang, Y. X. (2018). Hyper Local News Websites and Citizen Participation: Exploration and Analysis of the MinnPost in the US. New Media Research, 18, 136-137+142. (In Chinese) 